\title{
Eye health promotion in the South African primary health care system*
}

\author{
HL Sithole ${ }^{\dagger}$, and OA Oduntan*
}

†University of South Africa, Academic and Research Portfolio, Research Directorate, PO Box 392 , UNISA, 0003 South Africa

\$niversity of KwaZulu-Natal, Faculty of Health Sciences, Discipline of Optometry, Private Bag X 54001, Durban, 4000 South Africa

${ }^{\dagger}<$ sithohl@unisa.ac.za>

Received 3 June 2010; revised version accepted 19 November 2010

\begin{abstract}
Objective: There is currently very little or no research being done in South Africa on eye health promotion. Also, there is no evidence of any existing eye health promotion policy in the South African primary health care system. The purpose of this paper therefore is to highlight the lack of an integrated eye health promotion policy in the South African primary health care system.

Approach: A literature review of research databases was conducted to identify research done in the previous years pertinent to eye health promotion in South Africa. Also, documents were requested from the South African National Department of Health to ascertain claims of any existing guidelines on eye care. It was found that these documents included the national guidelines on prevention of blindness, refractive error screening for persons 60 years and older, cataract surgery in South Africa, management and control of eye conditions at primary level.
\end{abstract}

Although there is currently no integrated eye health promotion policy in South Africa, the fragmented national guidelines represent the existing policies on eye health promotion. The custodians of these policies are the eye care coordinators located in each of the nine provinces.

Conclusion: Although there are eye care coordinators in each province, there is no evidence of any eye health promotion activities being done in those provinces. Also, only one province out of nine has dedicated health promotion personnel that are not only focusing on eye health matters. This greatly compromises the initiatives of eliminating avoidable blindness. It is therefore recommended that an integrated eye health promotion model be developed so that it may form part of the South African primary health care system. (S Afr Optom 2010 69(4) 200-206)

Key words: Health promotion, health policies, eye health in South Africa

\section{Introduction}

Blindness is one of the most tragic but avoidable disabilities in the developing countries ${ }^{1}$. There are currently 45 million blind people and 135 million with low vision in the world ${ }^{2}$. The number of blind people

\footnotetext{
*The paper forms part of the work for the degree Doctor of Literature and Philosophy (DLitt et Phil) in Health Studies at the University of South Africa undertaken by HL Sithole with the guidance of Professors ON Makhubele-Nkondo and OA Oduntan.
} 
increases every year by two million and is expected to double by the year $2020 .^{2}$ This poses a serious threat to the "Vision 2020: right to sight" campaign initiated by the World Health Organization (WHO $)^{3}$. This campaign ${ }^{3}$ aims to prevent 100 million cases of blindness by the year 2020 .

South Africa has an estimated prevalence of blindness of about $0.75 \%$ of which $80 \%$ is avoidable 4 . The leading causes of blindness in South Africa are cataract (66\%) and glaucoma (14\%) and the majority of these people live in the rural areas ${ }^{4}$.

Many current health programmes arise from the realization that most ill health in society is socially, economically and culturally constructed, is often outside the individual's control, and requires social and political action ${ }^{5}$. Socio-political health promotion strategies can empower individuals to change their social reality ${ }^{6,7}$. Also, actions by individuals, families and communities, as well as eye care professionals are vital to achieving the "Vision 2020: the right to sight" target and this can only be achieved through effective health promotion ${ }^{8}$. Health promotion is the process of enabling individuals and communities to increase control over the determinants of health and thereby improving their health ${ }^{9}, 10$. The concept of health promotion was first elaborated in 1986 in the Ottawa Charter which set out five areas of activity in order to achieve health for all by the year 2000 and beyond ${ }^{9}$. These areas include:

i) Promoting health through public policy by focusing attention on the impact on health of public policies from all sectors through advocacy for health,

ii) Creating a supportive environment by assessing the impact on health of the environment and clarifying opportunities to make changes conducive to health,

iii) Developing personal skills by moving beyond the transmission of information to promote understanding, and to support the development of personal, social and political skills which enable individuals to take action to promote health,

iv) Strengthening community action by supporting concrete and effective community action in defining priorities, making decisions, planning strategies, and implementing them to achieve better health, v) Re-orienting health services by refocusing attention away from the responsibility to provide curative and clinical services towards the goal of health gain.

According to Hubley ${ }^{11}$, effective health promotion involves a combination of three components;

i) Health education directed at behaviour change to increase adoption of prevention behaviours and uptake of services,

ii) Improvements in health services such as the strengthening of patient education and increased accessibility and acceptability,

iii) And advocacy for improved political support for blindness prevention policies.

Most developing countries have adopted the Ottawa Charter and it has been integrated in the primary health care approach to deliver health care and health promotion ${ }^{12}$. The latter is not limited to health education. Health education is any planned activity that promotes health or prevents illness by changing behavior and it usually depends on experts to inform the public, and is usually focused on preventing illness ${ }^{13}$. In contrast, health promotion includes advocating for health needs, enabling people to achieve their health potential, and coordinating multiple sectors related to health promotion ${ }^{14}$.

\section{Health promotion in South Africa}

South Africa has a long history of commitment to a broader concept of health promotion both before and during legislated apartheid, but the introduction of the modern discipline of health promotion to the health system is fairly recent ${ }^{15}$. Health promotion ${ }^{16}$ first entered the South African health system in 1990. Since then, the South African Government has both undertaken significant institutional transformation, as well as sought to redefine most of the policies that determine the activities of the state in the management of social relations and service delivery including health services ${ }^{15}$.

The health care provided by the apartheid government was racially-based with large well equipped hospitals emerging in Afrikaner strongholds such as Pretoria, Stellenbosch and Bellville, while the facilities in the homelands were under-funded, under-equipped and under staffed ${ }^{15}$. The legacy for health education and promotion in government was 
both didactic and racist. In the 1980s progressive health organizations started to emerge ${ }^{17}$. People were beginning to be organized through community and workplace issues such as poor housing, lack of health services, poor transport services and campaigns around health were being linked to the broader social and political issues ${ }^{15}$.

Currently there is a Directorate of Health Promotion located within the Social Sector Cluster (SCC) within Primary Health Care (PHC), District and Development operations which falls under the Deputy Director General for Health Service Delivery in the National Department of Health (DoH). The action area for the SCC include among others:

i) Promotion of national identity and social cohesion,

ii) Comprehensive health care which addresses challenges of communicable and noncommunicable diseases,

iii) Meeting the increasing challenge of housing and human settlement,

iv) Food security and nutrition.

The government departments that constitute the SCC are Health, Social Development, Provincial and Local Government, Water Affairs, Tourism, Statistics South Africa, Transport, Labour, Education, Public Works, Public Services and Administration, Human Settlement, Minerals and Energy, Agriculture, Forestry and Fisheries, the Presidency and National Treasury. The Directorate of Health Promotion is one of several sections representing the Department of Health in the SCC and is headed by a Director. Each of the nine provincial governments has Health Promotion focal persons ${ }^{15}$.

\section{Eye health related policy and eye health promotion activities in SA}

The first significant piece of new policy for health promotion in South Africa appeared in the African National Congress (ANC) health policy document ${ }^{18}$. Drawing extensively on the policy processes both inside and outside the country, the ANC recognized the significant contribution that health promotion could make to strengthen its commitment to improving the health of South Africans and its vision for Primary Health Care (PHC).

Section 27 (1), Chapter 2 of the constitution of
South Africa ${ }^{19}$ states that everyone has a right to access to:

i) Health care services including reproductive health care,

ii) Sufficient food and water,

iii) Social security, including, if they are unable to support themselves and their dependants, appropriate social assistance.

Subsection (2) went further to state that, "The state must take reasonable legislative and other measures, within its available resources, to achieve the progressive realization of each of these rights".

Health promotion in South Africa is based on intersectoral collaboration. The governments (local, provincial and national) recognize that good health and well-being is dependant on a range of factors, many of which lie outside the health sector itself. The Health Sector strategic framework of 2004-2009 has 10 priorities most of which are health promotion ${ }^{20}$. Currently, health promotion service delivery is the responsibility of the national, provincial and local governments with provincial and local governments mainly implementing and the National Health Promotion Directorate offering support. There are also national non-government organizations (such as SOULCITY and LOVElife) and community based organizations operating across the country providing health promotion services. The result is that health promotion services are grossly proliferated with no single body coordinating activities. There is, therefore, a need for a well coordinated monitoring and evaluation of health promotion services.

The relationship between health and social determinants is well known to politicians and opinion leaders in South Africa. There is a commitment to doing something about health promotion by Health Ministers, with a desire to strengthen lifestyle campaigns and develop a more robust set of programs around non-communicable diseases and specifically around such issues as proper nutrition, hypertension and diabetes. There is also a commitment to intensify efforts to combat tuberculosis, to strengthen the implementation of the comprehensive plan for HIV and AIDS and to improve mental health services ${ }^{21}$.

There is a stable structure for health promotion service delivery at the national government level (The Directorate of Health Promotion) and health promotion focal persons in each province. Although 
each province has eye care coordinators, these are not necessarily concerned with eye health promotion activities. Also, there are disparities between provincial infrastructures. With the exception of one province (Mpumalanga), that has a career structure for Health Promotion Practitioners (HPPs), other provinces have either one officer or a skeletal staff responsible for health promotion with no established career path. Although the Mpumalanga example is not perfect, it offers some encouragement. Health promotion practice seems to be strong in Mpumalanga compared to other provinces. There is a career structure that makes it possible for HPPs to progress to Deputy Director's position. A recent audit in Mpumalanga ${ }^{22}$ places the number of HPPs at 120 with 34 that have received basic diploma training. This remarkable advancement of health promotion can be attributed to the dedication of the leadership of health promotion and political will on the part of the provincial authorities ${ }^{15}$.

There is a gross inadequacy of trained human resources for health promotion work within the Department of Health and indeed South Africa as a whole. This situation is difficult to justify given the financial resources available that can be utilized for manpower development in the country. For example, the expenditure on programs has seen steady growth, rising from R5.6 billion in 2001/02 to about R8.7 billion in 2007/08, an annual average increase of 7.6 per cent ${ }^{21}$. It is therefore plausible to conclude that there are resources to develop the technical capacity of health promotion professionals to provide expert policy advice and to implement programs ${ }^{15}$. Many influences on behavior including culture, economics, power, and tradition operate at the community level ${ }^{8}$.

A community based program is one which works within a geographically defined area, takes into account influences that operate at community level, and seeks to involve community members in the decision making process and in implementation ${ }^{23}$. The ideal situation is that the community decides its own health priorities, as well as solutions, and how these will be resourced, implemented, monitored, and evaluated. Unfortunately, this ideal is not always realized and the term 'community participation' has been loosely applied to a range of approaches from ones with full involvement of communities to 'top down' programs where all decisions are made externally ${ }^{24}$

In the early $1970 \mathrm{~s}$ in the former homeland of Gazankulu, community based approaches proved to have an impact on eye health knowledge and on the incidence of trachoma ${ }^{25}$. This shows the importance of some community based approaches in health promotion. Community involvement in health is mainly through the work of community based organizations and mobilization efforts of community health workers. As a democratic state, policies and guidelines for health actions receive wide consultation before they become operational. Although most health programs are vertical programs, links and partnership with community are developed. Communities are empowered to manage economic, environmental, social and cultural diversity. Most of this work is done by NGOs. There is significant community participation in policy and strategy development including the health promotion policy and strategy development including health promotion policy and strategy document development. Stakeholders from civil society organizations, community leaders, private sector organizations and business are widely consulted through a series of meetings in the policy development process ${ }^{15}$.

There is a routine monitoring and surveillance of the state of public health at the national level through the South African Demographic and Health Survey. In addition, public health research is conducted by the following:

i) National Research Institutions such as the Medical Research Council (MRC), Human Sciences Research Council (HSRC) and Health Systems Trust (HST),

ii) Academic institutions,

iii) International Centre for Eyecare Education (ICEE),

iv) South African Bureau for the Prevention of Blindness,

v) The media and other governmental information systems.

The research results are published and are readily available for use. The MRC has a health promotion 'Research and Development Group' that focuses on health promotion research. Also, the ICEE, through its 'giving sight' program, which aims at equipping ophthalmic nurses within the KwaZulu-Natal province to provide primary eye health care to the 
rural communities, is actively engaged in eye health promotion. This is a collaborative effort with WHO and the Vision 2020 project that aims at eliminating avoidable blindness.

The South African Eye Health Promotion Unit is located in the Directorate of Chronic Diseases, Disabilities and Geriatrics. Under this directorate, there are four national guidelines on different aspects of eye care as part of health promotion. These include the national guideline on the prevention of blindness in South Africa ${ }^{4}$, which concentrates on the prevention of avoidable blindness as a component of the vision 2020 global initiative. This guideline sets out four levels of prevention which include;

i) Primary prevention consists of measures to prevent diseases, injuries or conditions that can result in complications, impairments or disabilities. Such measures include health education, immunization, maternal and child health services, and safety promotion. All these measures comprise a major component of primary health care.

ii) Secondary prevention consists of early identification and intervention in the treatment of diseases, injuries or conditions to prevent the development of complications or impairments.

iii) Tertiary prevention consists of measures to limit or reduce impairments or disabilities.

iv) Quaternary prevention consists of measures to reduce the effect of untreatable disease or disability.

The objectives of the National Prevention of Blindness Programme included;

i) Provision of support to the Prevention of Blindness Programmes in South Africa and Southern African Development Community countries.

ii) Coordination of the Prevention of Blindness Programmes in South Africa.

iii) Promotion and protection of the rights of blind persons.

iv) Reduction of the prevalence of blindness in the country from $0.75 \%$ to $0.50 \%$ by the year 2005 . It is not known whether this has been achieved or not.

From the above mentioned objectives, the aspect of eye health promotion has not been adequately highlighted. This is a cause for a great concern considering that some of the leading causes of blindness in South Africa, such as refractive errors, could be avoided if health promotion was given adequate attention.

The second national guideline is on the management and control of eye conditions at primary level. The objectives of this guideline are;

i) To effectively manage eye conditions at primary level thereby limiting complications and potential blindness.

ii) To apply cost-effective interventions and accessibility to eye care for persons with eye diseases.

The above outlined objectives also do not include the aspect of health promotion. This shows that the national health strategy is curative driven. The third national guideline is on refractive error screening for persons 60 years and older. Although the purpose of this guideline is to deliver refraction services as an integral part of general health care and comprehensive eye care systems, it excludes the vast majority of South Africans who are also affected by refractive errors. Also, the guideline is silent on the issues of health promotion. The fourth guideline is on cataract surgery. Its main objectives include;

i) To correct blindness and impaired vision.

ii) To reduce the economic burden to the individual, family and community.

iii) To improve the quality of life of the individual.

These guidelines aim to promote health in the primary health care (PHC) clinics and community health centers $(\mathrm{CHC})$ by making available information on the availability and success of cataract surgery and marketing cataract surgery. This is a commendable exercise considering that each day in SA about 100 people become needlessly blind as a result of cataract $^{26}$.

Based on the experiences of currenthealth promotion activities in South Africa, the National Department of Health considered the settings approach to be crucial in driving the progress of health promotion. Since its implementation in 1999, the Health Promoting Schools initiative is considered by the National Health Promotion Directorate to be one of their greatest breakthroughs ${ }^{15}$. The departments of education and health worked together to develop and implement the school nutrition programs in 1999 and the Primary health care packages of South Africa (standards and norms) of 2001 was and is still used as a guide to enhance the process. The Department of Health, 
Department of Education, Department of Social Development and Population Welfare implemented a primary school nutrition program and school gardens for increasing food security in the families of the school children in need ${ }^{15}$. This initiative serves among other reasons, to supplement Vitamin A among school children. The incidence of Vitamin A deficiency is one of the leading causes of avoidable blindness among South African children ${ }^{4}$. Food insecurity is very common in South African households, though the solution could easily be found by growing fruit and vegetables in their backyards. It is a known fact, for instance, that children need vitamins and minerals to grow healthy and strong. Vitamin A, for example plays a role in protecting the body against infections. However, Vitamin A deficiency is severe in at least eight provinces in South Africa ${ }^{27}$ and about one in three South African children suffer from this deficiency 27. This problem is so severe that it has been declared a national health problem ${ }^{27}$.

Eye health promotion services in South Africa are fragmented and curative driven. According to Croasdale 28 , fragmented national guidelines on eye care represent eye health promotion policies. However, there is no integrated eye health promotion policy like the oral health promotion model which is still in a form of a draft ${ }^{29}$ and the nursing health promotion model. ${ }^{13}$ Also, there are different eye health promotion policies within the auspices of the eye care coordinators in every province ${ }^{28}$. However, there is no evidence on the effectiveness of eye health promotion strategies that are currently being used by the National Department of Health and its eyecare coordinators within all the provinces. Furthermore, there is no evidence whether such health promotion strategies are being implemented at all. This causes a great concern on the important aspect of health promotion that is not given the attention it requires.

Apart from the historical influences on the imbalances in eye health care, other factors have also had a significant impact on eye health. Demographic transition with rapid urbanization has resulted in unmet eye health needs, particularly in the disadvantaged and underserved communities.

\section{Conclusion}

It is known that South Africa does not have any policy dedicated solely to eye health promotion. The available guidelines are the only documents that have been developed and only give guidelines on curative measures rather than health promotion. Although there are eye care coordinators in each province, there is no evidence of any eye health promotion activities being done in those provinces. Also, only one province out of nine has dedicated health promotion personnel that are not only focusing on eye health matters. This greatly compromises the initiatives of eliminating avoidable blindness to a greater extent. It is therefore recommended that an integrated eye health promotion model be developed so that it may form part of the South African primary health care system.

\section{References}

1. Resnikoff S, Pascolini D, Etya'ale. Global data on visual impairment in the year 2002. Bull World Health Org 2004 82 844-851.

2. Roodhooft JMJ. Leading causes of blindness worldwide. Bull Soc Belge Ophthalmol 2002283 19-25.

3. Resnikoff S, Pararajasegaram R. Blindness prevention programmes: past, present, and future. Bull World Health Org 200179 222-226.

4. South African National Department of Health. National Guideline on Prevention of Blindness in South Africa. Directorate: Chronic Diseases, Disabilities and Geriatrics, December 2002.

5. MacDonald TH. Rethinking Health Promotion: a Global Approach. Routledge, London, 1998.

6. Sidell M. Community Action for Health. In The Challenge of Promoting Health: Exploration and Action. MacMillan, London, 1997.

7. Naidoo J, Wills J. Health Promotion: Foundations for Practice, 2nd ed. Bailliere Tindall, London, 2000.

8. Hubley J, Gilbert C. Eye health promotion and prevention of blindness in developing countries: critical issues. $\mathrm{Br} J \mathrm{Oph}$ thalmol 200690 279-284.

9. World Health Organization. Ottawa Charter for Health Promotion. An International Conference on Health Promotion. November 17-21 Copenhagen, WHO Regional Office for Europe, 1986.

10. Nutbeam D. Health promotion glossary. Health Promotion International 199813 349-364.

11. Hubley J. Communicating Health - An Action Guide to Health Education and Health Promotion, 2nd ed. Oxford: Macmillan, 2004.

12. World Health Organization. Strategic Directions for Strengthening Nursing and Midwifery Services. Geneva, Switzerland, 2002.

13. Uys LR, Majumdar B, Gwele NS. The KwaZulu-Natal Health Promotion Model. J Nur Sci 200436 192-196.

14. Dennil K. Aspects of Primary Health Care. Johannesburg, South Africa: International Thomson, 1999.

15. Onya H. Health promotion in South Africa. Promotion Health 200714 233-237. 
16. Coulson N. Health Promotion. In South African Health Review. The Health Systems Trust. The Press Gang, Durban, 2000.

17. Coulson N, Goldstein S, Ntuli A. Promoting Health in South Africa: An Action Manual. Heinemann, Sandton, Johannesburg, 1998.

18. African National Congress. The Reconstruction and Development Programme - A Policy Framework. Umunyana Publications, Johannesburg, 1994.

19. The Constitution of the Republic of South Africa. No. 38 of 1996.

20. Andrew G, Pillay Y. Priorities for the National Health System (2004-2009). In South African Health Review. Health System Trust, Durban 2005.

21. South African National Department of Health. South African Millenium Development Goals. Country Report: Department of Health, Pretoria, 2005.

22. Jooste HL. Audit Report on Health Promotion Practitioners and Services in Mpumalanga. Department of Health, Nelspruit, Mpumalanga, 2006.

23. Hubley J. Community participation-putting the community into community eye health. Community Eye Health 1999 1233.

24. Rifkin SB. Lessons from community participation in health programmes. Health Policy Planning 19861 240-249.

25. Sutter EE, Ballard RC. Community participation in the control of trachoma in Gazankulu. Soc Sci Med 198317 1813-1817.

26. South African National Department of Health. Guidelines for Cataract Surgery in South Africa, 2001.

27. The Sowetan (daily news publication). Report on Nation building, November 4, 2008.

28. Croasdale A. South African National Department of Health. Deputy Director; Chronic Diseases, Disabilities and Geriatrics (Personal communication, October 2, 2008).

29. Sithole T. South African National Oral Health Directorate (Personal communication, October 2, 2008). 